\title{
Impact of the Changes in Women's Characteristics over Time on Antenatal Health Care Utilization in Egypt (2000-2008)
}

\author{
Hassan H. M. Zaky 1,2,3*, Dina M. Armanious², Mohamed Ali Hussein ${ }^{4,5}$ \\ ${ }^{1}$ School of Humanities and Social Sciences, the American University in Cairo, Cairo, Egypt \\ ${ }^{2}$ Department of Statistics, Faculty of Economics and Political Science, Cairo University, Giza, Egypt \\ ${ }^{3}$ Social Research Center of the American University in Cairo, Cairo, Egypt \\ ${ }^{4}$ Faculty of Arts and Social Sciences, Kingston University, London, UK, \\ ${ }^{5}$ Faculty of Commerce, South Valley University, Qena, Egypt \\ Email: "hzaky@aucegypt.edu, dinamagdya@hotmail.com, m3ali83@yahoo.com
}

Received 26 July 2015; accepted 30 August 2015; published 2 September 2015

Copyright (C) 2015 by authors and Scientific Research Publishing Inc.

This work is licensed under the Creative Commons Attribution International License (CC BY).

http://creativecommons.org/licenses/by/4.0/

(c) (i) Open Access

\section{Abstract}

Objectives: This study empirically assesses the impact of the changes in women's characteristics, empowerment, availability and quality of health services on woman's decision to use antenatal care (ANC) and the frequency of that use during the period 2000-2008. Study Design: The study is a cross-sectional analytical study using 2000 and 2008 Egypt Demographic and Health Surveys. Methods: The assessment of the studied impact is conducted using the Zero-inflated Negative Binomial Regression. In addition, Factor Analysis technique is used to construct some of the explanatory variables such as women's empowerment, the availability and quality of health services indicators. Results: Utilization of antenatal health care services is greatly improved from 2000 to 2008. Availability of health services is one of the main determinants that affect the number of antenatal care visits in 2008. Wealth index and quality of health services play an important role in raising the level of antenatal care utilization in 2000 and 2008. However, the impact of the terminated pregnancy on receiving ANC increased over time. Conclusions: Further research of the determinants of antenatal health care utilization is needed, using more updated measures of women's empowerment, availability and quality of health services. In order to improve the provision of antenatal health care services, it is important to understand barriers to antenatal health care utilization. Therefore, it is advisable to collect information from women about the reasons for not receiving antenatal care.

\footnotetext{
${ }^{*}$ Corresponding author.
} racteristics over Time on Antenatal Health Care Utilization in Egypt (2000-2008). Open Journal of Obstetrics and Gynecology, 5, 542-552. http://dx.doi.org/10.4236/ojog.2015.510078 


\section{Keywords}

\section{Women's Characteristics, Antenatal Health Care, Women's Empowerment, Zero-Inflated Negative Binomial Regression, Egypt}

\section{Introduction}

Even though significant progress has been made in reducing maternal deaths globally since the 1990s, maternal mortality is unacceptably high. About 800 women die from pregnancy- or childbirth-related complications around the world every day. In 2013, 289,000 women died during and following pregnancy and childbirth. Almost all of these deaths occurred in low-resource settings, and most could have been prevented [1].

Antenatal care (ANC) remains one of the Safe Motherhood interventions that if properly implemented has the potential to significantly reduce maternal and perinatal mortalities. There is wide recognition that one of the major factors contributing to the high rate of adverse birth outcomes is the low use of antenatal and maternal health services [2].

While much has been written on the determinants of antenatal health care utilization in many countries [3]-[6], comparatively little is known about the determinants of the frequency of antenatal care visits [7]-[9]. The objectives of this study are twofold: First, the study seeks to examine the prevalence of ANC according to background characteristics, women's empowerment, availability and quality of health services in 2000 and 2008. Second, it aims at determining the impact of the changes in women's characteristics, empowerment, availability and quality of health services on number of ANC visits utilizing the Zero-inflated negative binomial regression in 2000 and 2008.

\section{Data and Methods}

\subsection{Data}

The study is a cross-sectional analytical study that depends on data derived from the Egypt Demographic and Health Surveys (EDHS 2000 and 2008). These surveys were conducted on behalf of the Ministry of Health $[\mathrm{MoH}]$, by El-Zanaty and Associates. The sample for the EDHS was selected randomly in three stages. The first stage included selecting the towns in urban areas and villages in rural areas. The second stage involved dividing the chosen towns and villages into parts of roughly equal population size then estimate of the number of households in each part. The third stage involved selecting the household sample. The EDHSs covered representative samples of 15,573 and 16,527 ever married women in the age group of 15 - 49 years in 2000 and 2008 respectively. Only married women aged 15 - 49 whose last birth was during the five-year period before each survey are included in the analysis because data about antenatal care was collected from only this sub-sample. They amounted to 8001 and 8036 women in 2000 and 2008 respectively.

\subsection{Methods}

Since the dependent variable namely, number of antenatal care visits, is considered count data, Poisson or negative binomial regression is used to analyze count data. To account for a large number of observations whose value is zero, Lambert (1992) suggested using "zero-inflated" count models. These are two-step models. The first step is used to model the probability of belonging to the zero-group vs. the non-zero group (a binary process) while the second step is a traditional count model (either Poisson or negative binomial regression) [10] [11]. In our data, the number of zeros is excessive where there are about 44 and 26 percent of women who did not receive antenatal health care in 2000 and 2008 respectively. Thus, the zero-inflated negative binomial model (ZINB) is used.

The explanatory variables are the place of residence, region, work status, age, wealth index, women's education, exposure to media (newspaper, TV and radio), husband's education, women's empowerment, and availability and quality of health services. To construct the wealth index variable, each household asset for which information was collected in the survey was assigned a weight or factor score generated through principal components analysis, and the resulting asset scores were standardized. The EDHS households were then assigned a 
standardized score for each asset, where the score differed depending on whether or not the household owned that asset. The scores were summed by household. Individuals were ranked according to the total score of the household in which they resided and divided into population quintiles, i.e., five groups with the same number of individuals in each.

The three variables women's empowerment, availability and quality of health services need special treatment as they are not readily available in the data used. The study constructs composite indicators to express them. These composite indicators are created by Exploratory Factor Analysis technique (EFA). There are several methods for obtaining factor extraction and rotation. This study uses principal component as an extraction method and VARIMAX as a rotation method.

The variables used to construct women's empowerment indicator are the participation of women in making decision about major household purchases namely daily household purchases, her health care, visiting family or relatives, how her husband's earnings (last variable only in 2008 EDHS) and her money are used, and the use of contraception. In addition, there are some other variables which represent whether or not it is a big problem for women to go to the doctor alone or even to get a permission to go to the doctor. Using these variables, Factor Analysis Technique is used to construct the indicator of women's empowerment in 2000 and 2008. Four factors are extracted and they explain about 73 and 71 percent of the total variations among the data in 2000 and 2008 respectively. Table 1 shows the rotated factor loadings for these factors. Internal consistency among all these variables is high (Cronbach's Alpha $=0.68$ and 0.71 in 2000 and 2008 respectively).

The results of the factor analysis show that the first factor includes five variables that explain women's empowerment in making decision namely; decision making about major household purchases, visits her family or relatives, her health care, daily household purchases, and how her husband's earnings is used (last variable only in 2008 EDHS). This factor explains about 27 percent of the variation whether in 2000 or 2008 EDHS and it represents "Making daily decisions". The second factor includes two variables, current contraceptive use and making decision about contraceptive use. This factor explains about 19 and 17 percent of the variation in 2000 and 2008 respectively, and it represents "Decision about contraceptive use". The third factor involves two variables, work status and making decision about how her money will be used. This factor explains about 16 percent of the variation whether in 2000 or 2008 EDHS and it represents "Control over her finances". The last factor includes two variables, getting permission to go to doctor and going to doctor alone. This factor explains about 11 percent of the total variation whether in 2000 or 2008 EDHS and it represents "Freedom of movement”.

In EDHS, women were asked to mention whether or not there is a problem on some issues related to the availability of health services. These issues are about distance to the health facility, having to take transportation,

Table 1. Rotated factor loadings of women's empowerment, EDHS 2000 and 2008.

\begin{tabular}{|c|c|c|c|c|c|c|c|c|}
\hline \multirow{3}{*}{ Variables } & \multicolumn{8}{|c|}{ Factors } \\
\hline & \multicolumn{2}{|c|}{ First } & \multicolumn{2}{|c|}{ Second } & \multicolumn{2}{|c|}{ Third } & \multicolumn{2}{|c|}{ Fourth } \\
\hline & 2000 & 2008 & 2000 & 2008 & 2000 & 2008 & 2000 & 2008 \\
\hline Major household purchases & 0.735 & 0.719 & 0.013 & 0.026 & 0.095 & 0.073 & 0.117 & 0.030 \\
\hline Daily household purchases & 0.667 & 0.683 & 0.050 & 0.075 & 0.012 & 0.052 & 0.170 & 0.010 \\
\hline Her health care & 0.731 & 0.767 & 0.004 & 0.049 & 0.071 & 0.005 & 0.149 & 0.064 \\
\hline Visits her family or relatives & 0.682 & 0.762 & 0.045 & 0.043 & 0.072 & 0.026 & 0.107 & 0.130 \\
\hline How her husband's earnings is used & - & 0.714 & - & 0.029 & - & 0.045 & - & 0.068 \\
\hline Work status & 0.105 & 0.061 & 0.035 & 0.007 & 0.985 & 0.982 & 0.052 & 0.041 \\
\hline How her money is used & 0.111 & 0.091 & 0.031 & 0.018 & 0.985 & 0.979 & 0.047 & 0.031 \\
\hline Current contraceptive use & 0.038 & 0.080 & 0.992 & 0.982 & 0.032 & 0.020 & 0.046 & 0.018 \\
\hline Decision about contraceptive use & 0.037 & 0.088 & 0.992 & 0.982 & 0.033 & 0.004 & 0.057 & 0.014 \\
\hline Getting a permission to go to the doctor & 0.144 & 0.141 & 0.035 & -0.010 & 0.044 & 0.016 & 0.790 & 0.763 \\
\hline Going to the doctor alone & 0.076 & 0.037 & 0.050 & 0.036 & 0.037 & 0.042 & 0.775 & 0.801 \\
\hline
\end{tabular}


and availability of female health provider (because some women do not prefer male health provider in Egypt). Factor Analysis Technique is used to construct the availability of health services indicator using the previous variables. One factor is extracted and this factor explains about 64 and 59 percent of the total variations among the data in 2000 and 2008 respectively and it represents the availability of health services. Internal consistency among these variables is moderate (Cronbach's Alpha $=0.68$ and 0.56 in 2000 and 2008 respectively).

Similarly, women who reported that they received antenatal care, tetanus toxoid injections, or other medical care unrelated to the pregnancy are asked whether they were weighed, their blood pressure measured, and urine and blood samples taken during any of the visits they made to a medical provider during their pregnancy. Those women are also asked whether they had been told about the signs of pregnancy complications, and, if they were told, whether they received any information about where to go if they experienced any complications. Finally, women are also asked whether they were given or had bought iron tablets or syrup. Using Factor Analysis Technique, two factors are extracted from these variables and they explain about 71 and 65 percent of the total variations among the data in 2000 and 2008 respectively. Table 2 shows the rotated factor loadings for these factors. Internal consistency among all these variables is high (Cronbach's Alpha $=0.81$ and 0.74 in 2000 and 2008 respectively).

The results of the factor analysis show that the first factor includes the following four variables: blood and urine sample taken, blood pressure measured, and woman was weighted. This factor explains about 53 and 47 percent of the variation in 2000 and 2008 respectively and it represents "content of antenatal care". The second factor includes the following two variables: woman was told about the signs of pregnancy complications and given or bought any iron tablets or syrup. This factor explains about 17 and 18 percent of the variation in 2000 and 2008 respectively and it represents "treatment with complications".

\section{Results}

According to WHO, a pregnant woman is considered to have received regular antenatal care if she mentioned that she had made at least four visits to a trained medical provider [12]. Almost 39 percent of women under consideration in the study in 2000 received regular antenatal care, while this percentage increased to 67 percent of women in 2008. Table 3 shows the prevalence of antenatal health care utilization according to background characteristics in 2000 and 2008. In addition, chi-square test is used to determine the significance of the relationship between antenatal health care and these characteristics. The results indicate that there is a statistically significant association between receiving regular antenatal heath care and place of residence, region, current age, women's education, husband's education, exposure to media and wealth index. For example in 2008, only 42 percent of women who are in the poorest quintile received regular antenatal care, while this percentage increased to 90 percent among women who are in the richest quintile. According to Table 3, the significance differences between 2000 and 2008 for each variable are examined by differences in Proportion Test. The results show that there are significant differences between 2000 and 2008 for each variable in receiving regular ANC. For example, only 28 percent of women in 2000 who live in rural areas received regular antenatal care, while this percentage increased to 59 percent of women in 2008. These results indicate that the changes in women' characteristics between 2000 and 2008 affect significantly the receiving of regular ANC during this period.

Table 2. Rotated factor loadings of quality of health services, EDHS 2000 and 2008.

\begin{tabular}{|c|c|c|c|c|}
\hline \multirow{3}{*}{ Variables } & \multicolumn{4}{|c|}{ Factors } \\
\hline & \multicolumn{2}{|c|}{ First } & \multicolumn{2}{|c|}{ Second } \\
\hline & 2000 & 2008 & 2000 & 2008 \\
\hline Blood pressure measured & 0.824 & 0.782 & 0.190 & 0.099 \\
\hline Blood sample taken & 0.887 & 0.799 & 0.152 & 0.186 \\
\hline Urine sample taken & 0.886 & 0.801 & 0.149 & 0.176 \\
\hline Weight & 0.795 & 0.782 & 0.110 & 0.071 \\
\hline Told about the signs of pregnancy complications & 0.108 & 0.158 & 0.808 & 0.776 \\
\hline Given any iron tablets or syrup & 0.170 & 0.099 & 0.766 & 0.804 \\
\hline
\end{tabular}


Table 3. Percentage and the proportion test of regular antenatal care utilization according to women's background characteristics (2000-2008).

\begin{tabular}{|c|c|c|c|c|}
\hline \multirow{2}{*}{\multicolumn{2}{|c|}{ Items }} & \multicolumn{2}{|c|}{ Regular ANC (4 visits or more) } & \multirow{2}{*}{ Difference } \\
\hline & & 2000 & 2008 & \\
\hline \multirow{3}{*}{ Place of residence ${ }^{*}$} & Urban & 54.8 & 80.9 & Sig. \\
\hline & Rural & 28.3 & 59 & Sig. \\
\hline & Urban governorates & 56.9 & 86 & Sig. \\
\hline \multirow{4}{*}{ Region $^{*}$} & Urban Lower Egypt & 56 & 79 & Sig. \\
\hline & Rural Lower Egypt & 34.9 & 65.6 & Sig. \\
\hline & Urban Upper Egypt & 51.7 & 75.9 & Sig. \\
\hline & Rural Upper Egypt & 21.1 & 50.5 & Sig. \\
\hline \multirow{8}{*}{ Current age $^{*}$} & Frontier governorates & 30.3 & 66.1 & Sig. \\
\hline & $15-19$ & 37.9 & 71.3 & Sig. \\
\hline & $20-24$ & 40.3 & 70.3 & Sig. \\
\hline & $25-29$ & 41.7 & 69.1 & Sig. \\
\hline & $30-34$ & 40.5 & 65 & Sig. \\
\hline & $35-39$ & 35.2 & 63.9 & Sig. \\
\hline & $40-44$ & 29.9 & 56.8 & Sig. \\
\hline & $45-49$ & 19.5 & 59.2 & Sig. \\
\hline \multirow{6}{*}{ Educational attainment ${ }^{*}$} & No education & 19.4 & 46.4 & Sig. \\
\hline & Incomplete primary & 29.7 & 58.7 & Sig. \\
\hline & Complete primary & 44.1 & 62.9 & Sig. \\
\hline & Incomplete secondary & 43.5 & 67.2 & Sig. \\
\hline & Complete secondary & 57.7 & 75.2 & Sig. \\
\hline & Higher & 73.6 & 90.1 & Sig. \\
\hline \multirow{2}{*}{ Work status* } & Not working for cash & 36.4 & 65.8 & Sig. \\
\hline & Working for cash & 56.5 & 78.6 & Sig. \\
\hline \multirow{2}{*}{ Reading newspaper ${ }^{*}$} & No & 26.6 & 62.8 & Sig. \\
\hline & Yes & 58.6 & 81.7 & Sig. \\
\hline \multirow{2}{*}{ Watching $\mathrm{TV}^{*}$} & No & 16.5 & 43.5 & Sig. \\
\hline & Yes & 40.4 & 68 & Sig. \\
\hline \multirow{2}{*}{ Listening to radio ${ }^{*}$} & No & 26.2 & 58.9 & Sig. \\
\hline & Yes & 41.8 & 73 & Sig. \\
\hline \multirow{3}{*}{ Terminated pregnancy ${ }^{* *}$} & No & 38.5 & 66.5 & Sig. \\
\hline & Yes & 40.9 & 70.9 & Sig. \\
\hline & Poorest & 15.4 & 42.4 & Sig. \\
\hline \multirow{3}{*}{ Wealth index ${ }^{*}$} & Poorer & 22.4 & 56.6 & Sig. \\
\hline & Middle & 36.6 & 65.9 & Sig. \\
\hline & Richer & 49 & 81 & Sig. \\
\hline \multirow{7}{*}{$\begin{array}{l}\text { Partner's educational } \\
\text { attainment }\end{array}$} & Richest & 70.6 & 90.1 & Sig. \\
\hline & No education & 19.3 & 46.7 & Sig. \\
\hline & Incomplete primary & 30.5 & 59.5 & Sig. \\
\hline & Complete primary & 30.6 & 67.3 & Sig. \\
\hline & Incomplete secondary & 38.5 & 64.5 & Sig. \\
\hline & Complete secondary & 49.3 & 71.6 & Sig. \\
\hline & Higher & 65.8 & 85 & Sig. \\
\hline \multicolumn{2}{|c|}{ Total } & 39 & 67 & Sig. \\
\hline
\end{tabular}

Source: Calculated by authors using EDHS, 2000-2008. ${ }^{*}$ Significant at level $1 \% .{ }^{* *}$ Significant at level 5\%. 
The study estimates the zero-inflated Negative Binomial (ZINB) model and the significant variables of the model are shown in Table 4. The coefficients of the output of the ZINB are interpreted as follow: the expected number of antenatal care visits changes by exp (coefficient) for each unit increase in the corresponding predictor while holding all other variables in the model constant [13].

The ZINB regression generates two separate models and then combines them. First, a logit model is generated for the certain zero cases predicting whether or not a woman would be in this group. Then, a negative binomial model is generated predicting the counts for those women who do not have zeros in their outcome variable. Finally, the two models are combined. However, both models should be specified: first the count model, then the model predicting the certain zeros [13], since there is interest in predicting the existence of excess zeros, (i.e., the probability that a woman will have zero visit) in addition to predicting the number of antenatal visits. Inflation equation refers to the logistic model which predicts whether or not a woman takes the value zero (did not receive antenatal care).

The results show that wealth index has a positive significant impact on number of antenatal care visits in 2000 and 2008. For example, the expected number of antenatal care visits for woman in the richest quintile is 1.41 and 1.24 times the expected number of antenatal care visits for woman in the poorest quintile while holding all other variables in the model constant in 2000 and 2008 respectively. Additionally, regarding the inflation model, the results show that the wealth index has a negative impact on the probability that women will have a zero visit. The probability of woman to be in the zero group decreases by 63 and 74 percent if it is in the richest quintile compared with woman in the poorest quintile in 2000 and 2008 respectively. As a result, the higher level of wealth index, the less likely the woman has a zero visit, and the higher predicted number of antenatal care visits in both 2000 and 2008.

The results of the fitted model show that the quality of health services has a positive impact on the number of antenatal care visits in 2000 and 2008. The expected number of antenatal care visits increases by almost one visit if the indicators of quality of health services increase by one unit while holding all other variables in the model constant. Additionally, the higher level of indicators of quality of health services, the less likely the women have zero visit.

The findings of this study show that the current age of women has a negative significant impact on the number of antenatal care visits in 2008. Increasing the current age of women by one year will decrease the expected number of antenatal care visits by almost one visit after controlling all other variables constant. On contrast, age of women does not affect the number of ANC visits in 2000. Additionally, regarding the inflation model, the higher the women's age, the more likely the women have zero visits in 2000 and 2008. Accordingly, women with higher age are less likely to go to receive antenatal care in 2000 and 2008 but less likely to increase the number of visits only in 2008.

The exposure to a terminated pregnancy (spontaneous miscarriages) has a significant impact on the number of antenatal care visits and the probability that women will have zero visits. The probability of woman to be in the zero group decreases by 21 and 48 percent if the woman had a terminated pregnancy in comparison with the woman did not have a terminated pregnancy in 2000 and 2008 respectively. Accordingly, the exposure to a terminated pregnancy increases the probability of receiving antenatal care and increases the number of antenatal care visits. However, the impact of the terminated pregnancy on receiving ANC increased over time due to the improvement in woman's awareness over time by the importance of ANC that can prevent any other pregnancy termination.

It can be noticed that region has a significant impact on the number of antenatal care visits. Table 4 shows that the expected number of ANC visits for woman from rural or urban Upper Egypt and frontier governorates are less than the expected number of ANC visits for woman from urban governorates. Moreover, the region has a significant impact on the probability that women will have a zero visit. For example, women from rural Upper Egypt are two and four times more likely to receive a zero visit than women from urban governorates in 2000 and 2008 respectively. This indicates that place of residence have higher impact on receiving ANC in 2008 than in year 2000.

As shown in Table 4, women's education increases the number of antenatal care visits in 2000, while woman with only university education or higher has significant impact on number of antenatal care visits in 2008. The percentage of educated women in year 2000 is very few, where only 30 percent of women have secondary education or more. Accordingly, increasing woman's education level will affect significantly the number of ANC visits. On the other hand, women' education levels increased in 2008, thus the university level is the only level 
Table 4. Results of ZINB regression for examining the determinants of number of antenatal visits (2000-2008).

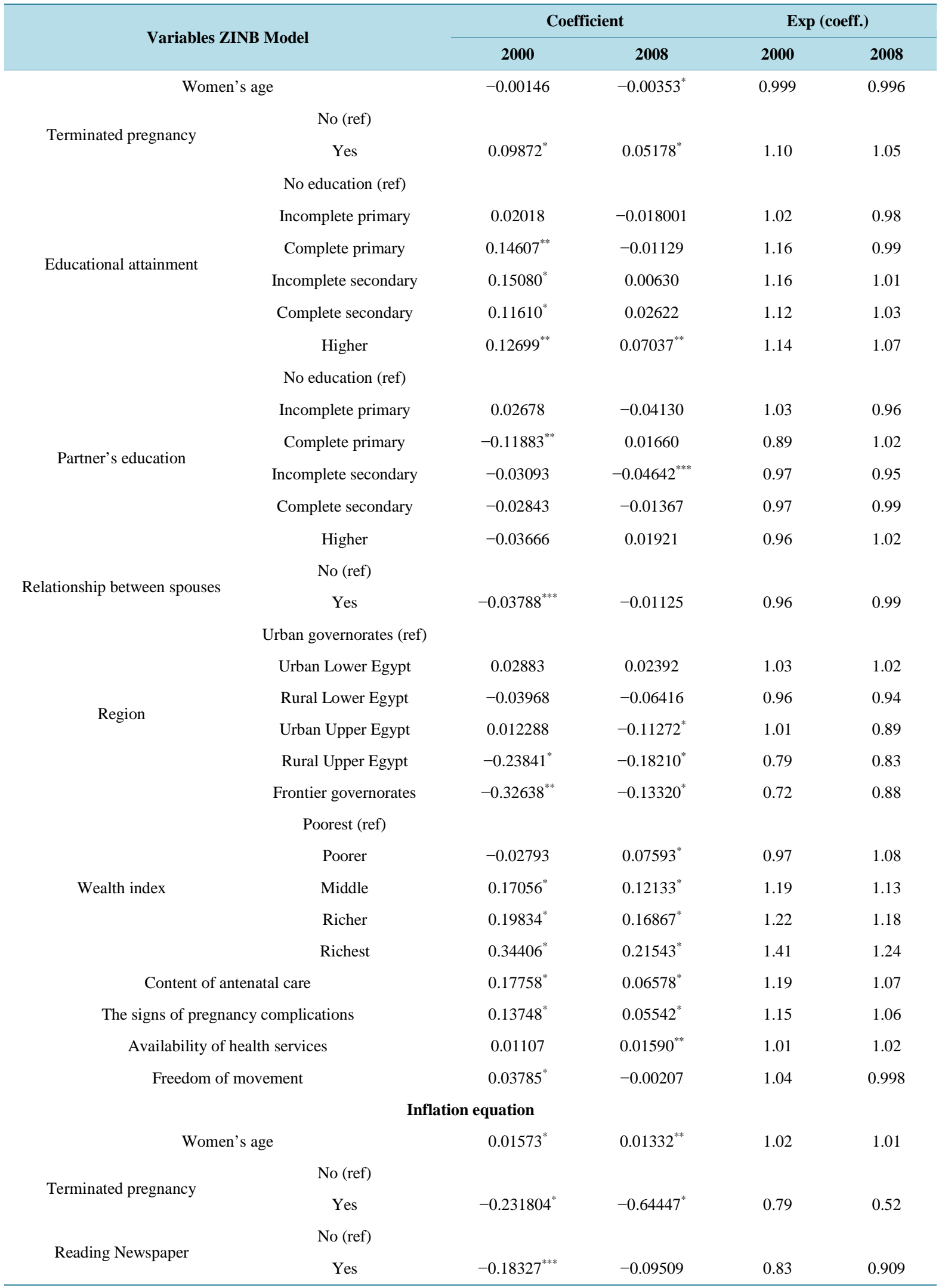




\section{Continued}

\begin{tabular}{|c|c|c|c|c|c|}
\hline \multicolumn{6}{|c|}{ No (ref) } \\
\hline Listemintry & Yes & $0.19637^{* *}$ & 0.00981 & 1.22 & 1.01 \\
\hline \multicolumn{6}{|c|}{ No education (ref) } \\
\hline \multirow{5}{*}{ Educational attainment } & Incomplete primary & 0.08681 & $-0.36928^{*}$ & 1.09 & 0.69 \\
\hline & Complete primary & 0.04987 & -0.27821 & 1.05 & 0.76 \\
\hline & Incomplete secondary & -0.00607 & $-0.36664^{*}$ & 0.99 & 0.69 \\
\hline & Complete secondary & -0.00646 & $-0.36096^{*}$ & 0.99 & 0.70 \\
\hline & Higher & $-0.62594^{* *}$ & $-0.55447^{*}$ & 0.53 & 0.57 \\
\hline \multicolumn{6}{|c|}{ No education (ref) } \\
\hline \multirow{5}{*}{ Partner's education } & Incomplete primary & -0.10413 & -0.19395 & 0.90 & 0.82 \\
\hline & Complete primary & -0.11272 & $-0.30388^{* * *}$ & 0.89 & 0.74 \\
\hline & Incomplete secondary & -0.02579 & $-0.21736^{* * *}$ & 0.97 & 0.80 \\
\hline & Complete secondary & -0.10374 & $-0.25882^{* *}$ & 0.90 & 0.77 \\
\hline & Higher & $-0.40857^{* *}$ & $-0.50292^{*}$ & 0.66 & 0.60 \\
\hline \multicolumn{2}{|c|}{ Difference at age between spouses } & $-0.01429^{* *}$ & -0.00282 & 0.99 & 0.997 \\
\hline \multirow{4}{*}{ Place of residence } & \multicolumn{5}{|l|}{ Rural (ref) } \\
\hline & Urban & 0.26544 & $0.57125^{* * *}$ & 1.30 & 1.77 \\
\hline & \multicolumn{5}{|l|}{ Urban governorates (ref) } \\
\hline & Urban Lower Egypt & 0.23451 & $0.52595^{*}$ & 1.26 & 1.69 \\
\hline \multirow{6}{*}{ Region } & Rural Lower Egypt & $0.65129^{* *}$ & $1.21496^{*}$ & 1.92 & 3.37 \\
\hline & Urban Upper Egypt & $0.43288^{*}$ & $0.55957^{*}$ & 1.54 & 1.75 \\
\hline & Rural Upper Egypt & $0.76133^{* *}$ & $1.44385^{*}$ & 2.14 & 4.24 \\
\hline & Frontier governorates & $0.79845^{*}$ & $0.57653^{* *}$ & 2.22 & 1.78 \\
\hline & Poorest (ref) & & & & \\
\hline & Poorer & $-0.20248^{* * *}$ & $-0.17466^{* * *}$ & 0.82 & 0.84 \\
\hline \multirow[t]{3}{*}{ Wealth index } & Middle & $-0.29577^{* *}$ & $-0.39754^{*}$ & 0.74 & 0.67 \\
\hline & Richer & $-0.66117^{*}$ & $-0.83993^{*}$ & 0.52 & 0.43 \\
\hline & Richest & $-0.98809^{*}$ & $-1.362201^{*}$ & 0.37 & 0.26 \\
\hline \multicolumn{2}{|c|}{ Content of antenatal care } & $-1.01609^{*}$ & $-0.746738^{*}$ & 0.36 & 0.47 \\
\hline \multicolumn{2}{|c|}{ The signs of pregnancy complications } & $-0.79742^{*}$ & $-0.616973^{*}$ & 0.45 & 0.54 \\
\hline \multicolumn{2}{|c|}{ Availability of health services } & 0.03999 & $-0.06316^{* * *}$ & 1.04 & 0.94 \\
\hline \multicolumn{2}{|c|}{ Decision about contraceptive use } & $0.09917^{*}$ & 0.02797 & 1.10 & 1.03 \\
\hline \multicolumn{2}{|c|}{ Freedom of movement } & $-0.08319^{* *}$ & 0.00028 & 0.92 & 1.00 \\
\hline \multicolumn{2}{|c|}{ Vuong test } & $27.22^{*}$ & $42.44^{*}$ & & \\
\hline \multicolumn{2}{|c|}{ Likelihood-ratio test } & $3570.72^{*}$ & $1357.95^{*}$ & & \\
\hline
\end{tabular}

Source: Calculated by authors using EDHS, 2000-2008. ${ }^{*}$ Significant at level $1 \%{ }^{* *}$ Significant at level 5\%. ${ }^{* * *}$ Significant at level $10 \%$.

that has significant impact on number of ANC. Additionally, regarding the inflation model, the results show that women's education and husband's education have a negative significant impact on the probability that woman will have a zero visit. The probability of woman to be in the zero group decreases by 47 and 43 percent if the woman has higher education in comparison with woman with no education in 2000 and 2008 respectively. 
As shown in Table 4, the availability of health services has a positive impact on the number of antenatal care visits only in 2008. The expected number of antenatal care visits increases by almost one visit if the availability of health services increase by one unit while holding all other variables in the model constant. Additionally, at only 2008 the higher level of availability of health services, the less likely the women have zero visit. In 2000, the health services are not widespread as in 2008 and suffer from the absence of the antenatal care services, for that reason, the availability of health services variable is not significant in 2000, but it has a significant impact on increasing the number ANC visits in 2008.

Table 4 shows that only the freedom of movement from the indicators of women's empowerment has a positive impact on the number of antenatal care visits in 2000. The expected number of antenatal care visits increases by almost one visit if the level of freedom of movement increases by one unit.

Vuong test compares the zero-inflated negative binomial model to a standard negative binomial model [13]. Because the z-value is significant, the Vuong test shows that the zero-inflated negative binomial is a better fit than the standard negative binomial. Also, the likelihood ratio test compares the zero-inflated negative binomial model versus the zero-inflated Poisson model [13]. A significant likelihood ratio test for alpha $=0$ indicates that our data is over dispersed and that a zero-inflated negative binomial model is more appropriate than a zero-inflated Poisson model.

\section{Discussion}

The results indicate that the availability of health services has a positive impact on antenatal care attendance and the frequency of its use at only 2008. This indicates that the government has succeeded in making health services more accessible during the period 2000-2008 as well as female health workers, who visit women in their houses and increase their awareness of receiving antenatal care, became more available. This finding is supported by a study in Haiti and Ghana where they found that distance influences antenatal care attendance and any increase in distance to the nearest health facility led to fewer antenatal visits [2] [14].

Consistent with the general findings of earlier studies [6]-[8] [15] [16], household wealth is an important predictor of both antenatal care attendance and the number of antenatal care visits. It is proved that high economic status has a positive relationship to the number of antenatal care visits at 2000 and 2008 . The results that women living in the poorest regions of a country are less likely to access antenatal care than those living in the non-poor regions may reflect remoteness, poor road and health infrastructure, limited access to information, poor access to health services and strong adherence to traditional values [5]. In addition, women from high economic status can often afford to pay for health services and any associated travelling costs.

Women's age is found to have a negative impact on antenatal care attendance and the repeated visits. These findings agree with the literature in India, it is proved that the younger mothers are more likely to receive antenatal health care than older mothers [17].

Consistent with previous research, the likelihood of using any antenatal care and the repeated visits are both strongly influenced by the level of education of the pregnant woman and that of her husband [4] [5] [8] [14] [15]. A higher level of education would increase the woman's knowledge, awareness and effectiveness of antenatal services and the consequences. This knowledge could influence her healthcare decision-making. Lack of knowledge of obstetric complications was associated with underutilization of antenatal services in Indonesia [18].

A significantly positive relationship is observed between the quality and utilization of antenatal care in 2000 and 2008. This confirms previous studies in India and Egypt which showed that the higher level of quality of health services, the higher level of antenatal care utilization [9] [19].

\section{Conclusions}

This study tries to examine the impact of the changes in women's characteristics and availability and quality of health services on number of antenatal health care visits utilizing the Zero-inflated negative binomial regression in 2000 and 2008. To achieve the goals of this study, indicators of women's empowerment, availability and quality of health services are constructed using factors analysis technique. The results indicate that the utilization of antenatal health care services is greatly improved from 2000 to 2008.

The findings show that the availability of health services is one of the main determinants of number of antenatal care visits only in 2008. Therefore, it is important that public health strategies take into account the availability and accessibility of health services. Overall, the quality of health services is found to be an important 
predictor of antenatal care attendance and the repeated visits in 2000 and 2008. Therefore, it is important to collect information about how women who had antenatal care are satisfied with the services offered to them and the problems they face during receiving the antenatal care to solve these problems and improve the quality of the services.

It can be noticed that wealth index plays an important role in raising the level of antenatal care utilization in 2000 and 2008. For that reason, more governmental intervention is advised to improve women's economic status and increase their awareness of the risks they might be exposed in order to encourage them to utilize antenatal health care services. Moreover, many non-governmental organizations have targeted poor women to promote the use of antenatal care and the frequency of its use by expanding maternal health programmes, especially in those areas with a poor health infrastructure or suffering from extreme poverty.

Overall, the education level of both mothers and their partners are found to be an important predictor of the decision to seek antenatal care services. Also, women from rural or urban Upper Egypt receive antenatal care less than women from urban governorates. Therefore, health promotion programs about antenatal care are advisable to target less educated women and women at Upper Egypt for increasing community awareness about the necessity of antenatal services.

Further research of the determinants of antenatal health care utilization is needed, using more updated measures of women's empowerment, availability and quality of health services, which are advised to draw more robust empirical results. Reasons for not receiving regular antenatal care are not recorded in DHS. In order to improve the provision of antenatal health care services, it is important to understand barriers to antenatal health care utilization. Therefore, it is advisable to collect information from women about the reasons for not receiving antenatal care. In addition, it is suggested to use the most recent DHS data in 2014 once available, for public use, to update the trends and patterns in antenatal care services.

\section{Author's Statement}

This study uses secondary data so it does not require any ethical approval. There are no competing interests and no funding was received.

\section{References}

[1] World Health Organization (WHO) (2014) Facts Sheet: Maternal Mortality. http://www.who.int/mediacentre/factsheets/fs348/en/

[2] Asundep, N.N., Carson, A.P., Turpin, C.A., Tameru, B., Agidi, A.T., Zhang, K., et al. (2013) Determinants of Access to Antenatal Care and Birth Outcomes in Kumasi, Ghana. Journal of Epidemiology and Global Health, 3, $279-288$. http://dx.doi.org/10.1016/j.jegh.2013.09.004

[3] Furuta, M. and Salway, S. (2006) Women's Position within the Household as a Determinant of Maternal Health Care Use in Nepal. International Family Planning Perspectives, 32, 17-27. http://dx.doi.org/10.1363/3201706

[4] Kamiya, Y. (2011) Women's Autonomy and Reproductive Health Care Utilization: Empirical Evidence from Tajikistan. Health Policy, 102, 304-313. http://dx.doi.org/10.1016/j.healthpol.2011.04.001

[5] Pebley, A., Goldman, N. and Rodriguez, G. (1996) Prenatal and Delivery Care and Childhood Immunization in Gautemala: Do Family and Community Matter? Demography, 33, 231-247. http://dx.doi.org/10.2307/2061874

[6] Zaky, H.H., Armanious, D.M. and Hussein, M.A. (2014) Testing for the Endogenous Nature between Women's Empowerment and Antenatal Health Care Utilization: Evidence from a Cross-Sectional Study in Egypt. BioMed Research International, 2014, Article ID: 403402.

[7] Bloom, S.S., Wypij, D. and Gupta, M.D. (2001) Dimensions of Women's Autonomy and the Influence on Maternal Health Care Utilization in a North Indian City. Demography, 38, 67-78. http://dx.doi.org/10.1353/dem.2001.0001

[8] Gage, A. (2007) Barriers to the Utilization of Maternal Health Care in Rural Mali. Social Science and Medicine, 65, 1666-1682. http://dx.doi.org/10.1353/dem.2001.0001

[9] Zaky, H.H., Armanious, D.M. and Hussein, M.A. (2012) Impact of Women's Empowerment and Other Indicators on Antenatal Health Care Utilization in Egypt. Proceedings of the Annual Meeting of Population Association of America (PAA’12), San Francisco.

[10] Cameron, A.C. and Trivedi, P.K. (2005) Microeconometrics: Methods and Applications. Cambridge University Press, New York. http://dx.doi.org/10.1017/CBO9780511811241

[11] Lambert, D. (1992) Zero-Inflated Poisson Regression, with an Application to Defects in Manufacturing. Technometrics, 
34, 1-14. http://dx.doi.org/10.2307/1269547

[12] World Health Organization (WHO). Media Centre: New Releases 2004. [Cited 2013 Sep 30]. http://www.who.int/mediacentre/news/releases/2004/pr22/en/

[13] Institute for Digital Research and Education (IDRE). Stata Annotated Output. [Cited 2014 Aug 28]. http://statistics.ats.ucla.edu/stat/stata/output/Stata_ZINB.htm

[14] Alexandre, P.K., Saint-Jean, G., Crandall, L. and Fevrin, E. (2005) Prenatal Care Utilization in Rural and Urban Areas of Haiti. Revista Panamericana de Salud Pública, 18, 84-92. http://dx.doi.org/10.1590/S1020-49892005000700002

[15] Sepehri, A., Sarma, S., Simpson, W. and Moshiri, S. (2008) How Important Are Individual, Household and Commune Characteristics in Explaining Utilization of Maternal Health Services in Vietnam? Social Science and Medicine, 67, 1009-1017. http://dx.doi.org/10.1016/j.socscimed.2008.06.005

[16] Singh, A., Mukherjee, S. and Chandra, R. (2012) Inter-District Variation in Socio-Economic Inequalities in Maternal Healthcare Utilization in Rural Assam, 2007-2008. Journal of North East India Studies, 2, 94-103.

[17] Sharma, V., Mohan, U., Das, V. and Awasthi, S. (2012) Utilization Pattern of Antenatal Care in Lucknow under National Rural Health Mission. Indian Journal of Community Health, 24, 32-36.

[18] Titaley, C.R., Dibley, M.J. and Roberts, C.L. (2010) Factors Associated with Underutilization of Antenatal Care Services in Indonesia: Results of Indonesia Demographic and Health Survey 2002/2003 and 2007. BMC Public Health, 10, 485-494. http://dx.doi.org/10.1186/1471-2458-10-485

[19] Rani, M., Bonu, S. and Harvey, S. (2007) Differentials in the Quality of Antenatal Care in India. International Journal for Quality in Health Care, 20, 62-71. http://dx.doi.org/10.1093/intqhc/mzm052 